\title{
Experimental models of microcystin accumulation in Daphnia magna grazing on Planktothrix rubescens: Implications for water management
}

\author{
Shiva Shams ${ }^{\mathrm{a}, \mathrm{b}, *}$, Leonardo Cerasino ${ }^{\mathrm{a}}$, Nico Salmaso ${ }^{\mathrm{a}}$, Daniel R. Dietrich ${ }^{\mathrm{b}}$ \\ a IASMA Research and Innovation Centre, Istituto Agrario di S. Michele all'Adige, Fondazione E. Mach, Via E. Mach 1, 38010 S. Michele all'Adige (Trento), Italy \\ ${ }^{\mathrm{b}}$ Human and Environmental Toxicology Group, Department of Biology, University of Konstanz, P.O. Box X-918, D-78457 Konstanz, Germany
}

Keywords:

Planktothrix rubescens

Cyanobacteria

Daphnia magna

Microcystins

Bioaccumulation

Lake Garda

\begin{abstract}
A B S T R A C T
In this study, we investigated the kinetic aspects of the microcystin (MC) transfer from Planktothrix rubescens to Daphnia magna by carrying out exposure experiments in small simple mesocosms. We hypothesized that higher fractions of toxic cyanobacteria in the diet of grazers would shift the balance towards a greater than linear, i.e. non-linear accumulation of MC in D. magna. This hypothesis was tested by exposing $D$. magna to varying initial densities of MC-producing $P$. rubescens. The evolving models of MC accumulation differed largely as a result of the duration of exposure and initial MC concentrations used. Within the first $24 \mathrm{~h}$ of exposure, MC accumulation in D. magna was linear, irrespective of the initial densities of toxic P. rubescens and thus MC concentrations. After $48 \mathrm{~h}$ of exposure, MC accumulation in D. magna showed an exponential pattern, possibly due to a delayed digestion of $P$. rubescens and/or decreased MC detoxification capabilities when compared with higher ambient concentrations of MC. After $72 \mathrm{~h}$ toxin concentrations in Daphnia drop in all experiments as a consequence of the reduced cyanobacterial cells in the medium and the detoxification of MC within Daphnia. The results obtained suggest that in lakes with higher MC content and longer cyanobacterial bloom period MC accumulation in D. magna should be more pronounced than in mesotrophic lakes with lower MC content. The latter interpretation, however, should be verified investigating accumulation of MC both in larger mesocosms and in situ, in lakes of different trophic status.
\end{abstract}

\section{Introduction}

Cyanobacterial blooms have become a growing global concern due to their increased occurrence as well as to the massive increase of freshwater utilization throughout the world (Paerl et al., 2011). Many cyanobacterial species are able to produce a wide range of toxins (Sivonen and Jones, 1999; Sivonen and Börner, 2008). One of the more intensely studied toxin groups is represented by microcystins (MCs) (Metcalf and Codd, 2012). So far, more than 110 different variants of MCs have been reported (Dietrich and Hoeger, 2005; Spoof, 2005; Puddick, 2013), primarily produced by freshwater cyanobacteria, e.g. Microcystis, Planktothrix, Anabaena, and occasionally Nostoc (Sivonen and Jones, 1999; Salmaso et al., 2013). MCs are cyclic heptapeptides that consist of $5 \mathrm{D}-$ and 2 variable Lamino acids. They are characterized by high chemical stability. The degradation of MCs in water occurs very slowly, and is primarily the result of microbial breakdown and to a lesser extent the result of

\footnotetext{
* Corresponding author at: IASMA Research and Innovation Centre, Istituto Agrario di S. Michele all'Adige, Fondazione E. Mach, Via E. Mach 1, 38010 S. Michele all'Adige (Trento), Italy. Tel.: +390461615531.

E-mail address: shiva.shams@fmach.it (S. Shams).
}

photolytic and hydrolytic processes (Tsuji et al., 1994). Due to their stability, MCs have the capability of being accumulated in a variety of aquatic organisms including bivalves, crustaceans, zooplankton and fish (Ferrão-Filho et al., 2002; Zhang et al., 2009; Ernst et al., 2007, 2009; Lemaire et al., 2012; Wojtal-Frankiewicz et al., 2013).

There has been growing attention towards the effects of MCs on zooplankton and especially on the larger cladoceran Daphnia because of the key role that these organisms have in the aquatic food web (Elser, 1999; Benndorf et al., 2002; Reichwaldt et al., 2013). They feed on primary producers and represent a major source of food for juvenile fish, consequently they can act as transfer vectors of toxins to higher trophic levels (Rohrlack et al., 2005). Unlike copepods, which appear to be able to discriminate between toxic and non-toxic cells (DeMott and Moxter, 1991), daphnids are non-selective filter feeders and are a priori not able to select food particles that differ in quality (DeMott, 1986). However, Daphnia pulicaria was demonstrated to be able to discriminate between toxic and non toxic Microcystis aeruginosa cells, whereby MC content was obviously not the determining factor for reducing filter feeding when $D$. pulicaria was confronted with toxic $M$. aeruginosa (Jungmann et al., 1991; Jungmann, 1995).

Several investigations have shown that filamentous cyanobacteria have a negative effect on Daphnia because of the interference 
of filaments with grazing on other available food sources (Porter and McDonugh, 1984; Hawkins and Lampert, 1989; Kurmayer and Jüttner, 1999). Kurmayer (2001) reported that Daphnia galeata was able to ingest the filamentous cyanobacterium Aphanizomenon flexuosum and that mechanical interference was not important. Nadin-Hurley and Duncan (1976) have argued that the width of filaments is more important than length in limiting ingestion by daphnids, while DeMott (1995) suggested that filament size together with filament hardness are important for Daphnia feeding on large particles. Oberhaus et al. (2007) finally reported that $D$. pulicaria preferred to graze on short filaments of Planktothrix rubescens and $P$. agardhii and could efficiently control Planktothrix blooms in their early stages. Above results highlight the complexity of feeding mechanisms underlying grazing of filamentous cyanobacteria by Daphnia, whereby the specific feeding preferences appear to be largely dependent on the Daphnia and cyanobacteria species involved (Hulot et al., 2012). Nevertheless, in spite of the widespread occurrence of toxic Planktothrix in European lakes (Davis et al., 2003; Salmaso et al., 2003; Ernst et al., 2009), Daphnia grazing on filamentous cyanobacteria has been investigated so far by only a limited number of studies (see e.g. Kurmayer and Jüttner, 1999; Oberhaus et al., 2007; Pires et al., 2007; Reichwaldt and Abrusan, 2007).

Adverse effects of MC on Daphnia have been reported by many studies, e.g. laboratory experiments by DeMott (1999) investigated the effects of $M$. aeruginosa on five different Daphnia species. Out of the five species tested, $D$. pulicaria showed the lowest growth inhibition and $D$. pulex the highest. D. galeata, instead, exhibited symptoms of exhaustion that finally led to death (Rohrlack et al., 2005). Recently, Dao et al. (2010) provided evidence that offspring produced by Daphnia magna pre-exposed to MC-LR or cyanobacteria crude extract, not only showed delayed maturation but also increased mortalities.

A few other studies explored the accumulation of MCs in large cladocerans. Thostrup and Christoffersen (1999) in a laboratory experiment documented that $D$. magna grazing on $M$. aeruginosa could lead to an accumulation of MCs up to $24.5 \mu \mathrm{g} \mathrm{g}^{-1}$ dry weight. Similarly, Oberhaus et al. (2007) demonstrated that D. pulicaria was able to accumulate MCs up to $1099 \mu \mathrm{gg}^{-1}$ dry weight when grazing on filaments of Planktothrix. Nevertheless, the accumulation kinetics of $\mathrm{MC}$ in large cladocerans was poorly investigated. At the same time, no information was available regarding the type of relationships governing $\mathrm{MC}$ accumulation as a function of exposure time and ambient MC concentrations.

Following the observed feeding behaviours of $D$. pulicaria towards toxic and non-toxic small-celled M. aeruginosa, the question was raised whether feeding on different proportions of toxic and non-toxic filaments would result in different MC accumulation patterns in exposed daphnids.

On the basis of above considerations we decided to investigate the MC accumulation patterns in D. magna after exposure to populations of Planktothrix rubescens with different proportions of toxic and non toxic strains. Assuming that accumulation occurs when a positive net balance exists between MC uptake and concomitant MC loss resulting from excretion and detoxification (e.g. oxidation and/or conjugation), we hypothesized that higher concentrations of toxic filaments would result in a proportionally higher and non-linear accumulation of MC in Daphnia. More specifically, we analyzed the suitability of linear and exponential models for explaining the relationships between MC accumulation in Daphnia, ambient MC concentrations, and both initial MC exposure and time after initial exposure. The results will be discussed also taking into considerations the implications for water management in lakes of different trophic status and abundance of Planktothrix.

\section{Materials and methods}

\subsection{Chemicals and analytical equipment}

Solvents and reagents used for toxin extraction and analysis were LC-MS purity grade. MC (including [D-Asp ${ }^{3}$ ] MC-RR) analytical standards were purchased from Sigma-Aldrich. The ultrasonic homogenizer was an Omni Sonic Ruptor 4000 equipped with a processing tip of $4 \mathrm{~mm}$ in diameter. The LC-MS system consisted of a Waters Acquity UPLC ${ }^{\circledR}$ directly coupled to an AB Sciex 4000 QTRAP hybrid triple quadrupole-linear ion trap mass spectrometer (Cerasino and Salmaso, 2012).

\subsection{P. rubescens and D. magna cultures}

Single filaments of toxic and non-toxic P. rubescens were isolated at the Long Term Ecological Research (LTER) station of Lake Garda (Lat $45^{\circ} 41^{\prime \prime} \mathrm{N}$, Long $10^{\circ} 43^{\prime} 15^{\prime \prime} \mathrm{E}$ ) and cultured in flasks containing BG11 medium in a temperature-controlled chamber at $15^{\circ} \mathrm{C}$ with $8: 12 \mathrm{~h} \mathrm{light}$ :dark cycle and a light intensity of $30 \mathrm{mmol}$ photon $\mathrm{m}^{-2} \mathrm{~s}^{-1}$. Cultures were periodically analyzed for density and MC content. Toxic cultures contained only one toxin, namely [DAsp $^{3}$ ] MC-RR.

D. magna batches were provided by Eschematteo srl, Italy. Daphnia were cultured in a glass aquarium filled with dechlorinated tap water in a temperature-controlled chamber at $15^{\circ} \mathrm{C}$ with $8: 12 \mathrm{~h}$ light:dark cycle and a light intensity of $30 \mu \mathrm{mol}$ photon $\mathrm{m}^{-2} \mathrm{~s}^{-1}$. Daphnia were fed with cultures of green algae (Scenedesmus sp.) and baking yeast (Saccharomyces cerevisiae). The yeast was resuspended in water before feeding.

\subsection{Experimental setup}

To investigate MC accumulation, 100 adult $D$. magna were put into $1 \mathrm{~L}$ glass beakers filled with $P$. rubescens cultures with $\mathrm{MC}$ concentrations of 9.0, 3.8, 2.4 and $0.6 \mu \mathrm{gl}^{-1}$, hereafter referred as exposures A, B, C and D. In order to achieve the different MC concentrations, different proportions of toxic and non-toxic strains of $P$. rubescens were mixed and diluted with BG11 medium to $1 \mathrm{~L}$. A control group was used containing a comparable density of the chlorophyte Scenedesmus sp.

Exposures B-D contained the same density of $P$. rubescens (approx. 54,000 cells ml-1), while exposure A contained approx. 22,000 cells $\mathrm{ml}^{-1}$. All beakers were placed in a temperaturecontrolled climatic chamber at $15^{\circ} \mathrm{C}$ with $8: 12 \mathrm{~h}$ light:dark cycle and a light intensity of $30 \mu \mathrm{mol}$ photons $\mathrm{m}^{-2} \mathrm{~s}^{-1}$. Neither exposure medium (BG11) nor P. rubescens (exposures) and Scenedesmus (controls) were exchanged or replenished during the exposures. $P$. rubescens and Scenedesmus density as well as total MC concentrations in the exposure medium and in exposed and control daphnids were determined at $0,6,24,48,72$, and $144 \mathrm{~h}$ of exposure. The fate of different densities of $P$. rubescens over time without concurrent grazing pressure was examined in parallel experiments in which $P$. rubescens cultures were diluted at the required densities with the same BG11 medium and kept in the same conditions of the Daphnia-containing treatments. All the analyses (MC content and algal densities) were made on three independent replicates, with the exclusion of the densities of Planktothrix in the experiments with Daphnia (cf. Fig. 1).

\subsection{Algal density estimation}

Densities of P. rubescens were determined by counting of Lugol's fixed water sub-samples $(1-2 \mathrm{ml})$ taken from each exposure at the sampling times described above. After dilution, Lugol's fixed samples were counted using the standard inverted microscopic method 

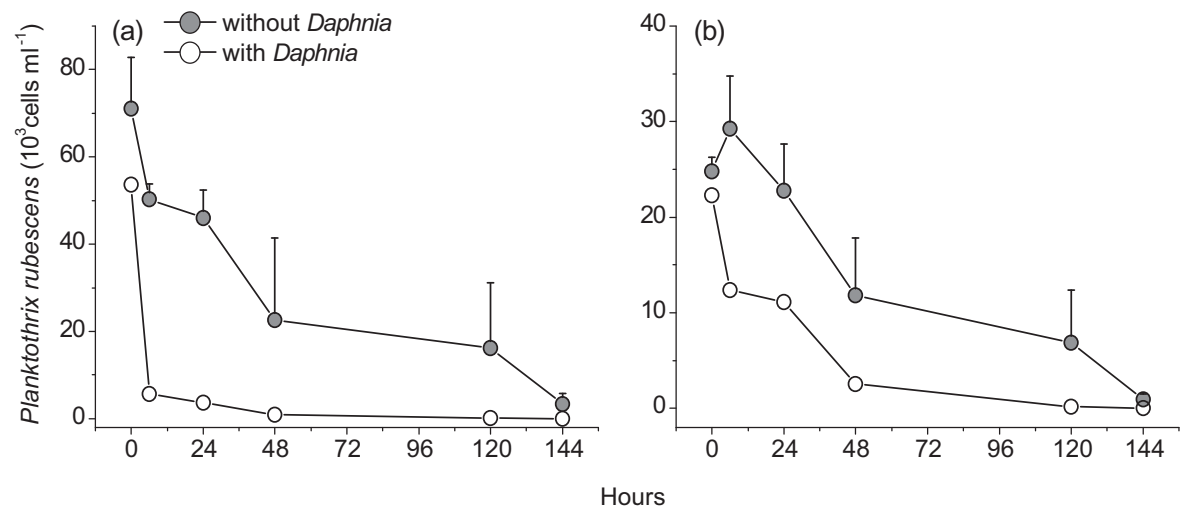

Fig. 1. Decrease of $P$. rubescens over time in experiments with and without $D$. magna at two different $P$. rubescens densities. (Starting densities (a): 71,025 cells ml ${ }^{-1}$ without daphnia and 53,630 cells ml ${ }^{-1}$ with daphnia present; (b): 24,771 cells ml $^{-1}$ without daphnia and 22,280 cells ml ${ }^{-1}$ with daphnia present.) Values "without Daphnia" are mean \pm SEM (standard errors of the means) of $n=3$ replicate experiments. Note the different scales of the $y$-axis in (a) and (b).

using $10 \mathrm{ml}, 2.5 \mathrm{~mm}$-diameter sedimentation chambers (Lawton et al., 1999). Planktothrix densities were estimated by determining the length of filaments in 5 equidistant transects at $200 \times$ (width of the optical field, $1 \mathrm{~mm}$ ) located on the bottom of the sedimentation chamber, and then dividing the total length of filaments by the length of one cell $(5 \mu \mathrm{m})$. The procedure and the reliability of this type of density estimation for filamentous species were previously reported by Rott et al. (2007).

\subsection{Toxin extraction and analysis}

The content of MC in both D. magna and water was analyzed via LC-MS/MS. For MC extraction from D. magna, 15 Daphnia were randomly collected from the exposure beakers using a pipette with a large tip, gently rinsed twice with distilled water to remove any algae attached to the daphnids, transferred to Eppendorf-tubes with $1 \mathrm{ml}$ of water and then subjected to freeze-thawing. For MC extraction from water, $1 \mathrm{ml}$ water sample taken from each exposure was freeze-thawed. MC-extracts of Daphnia and water samples were prepared by adding $1 \mathrm{ml}$ methanol to $1 \mathrm{ml}$ sample volume. This mix was probe-sonicated for $8 \mathrm{~min}$ at $120 \mathrm{~W}$ in pulsed mode and then filtered through $0.2 \mu \mathrm{m}$ filter. The filtrate was analyzed via LC-MS within $24 \mathrm{~h}$ of preparation. A more detailed description of the analytical procedures is provided in Guzzella et al. (2010) and Cerasino and Salmaso (2012). This method should allow estimation of the overall MC content within Daphnia, i.e. including both the metabolized fraction and the fraction contained inside the filaments trapped in the carapace and phyllopods. For experiment A, MC concentrations at time $=0$ were not measured, therefore initial MC concentrations for this experiment were inferred from a model relating MC measured after 0 and $6 \mathrm{~h}$ in experiments $B$ and $\mathrm{C}\left(r^{2}=0.93\right)$.

\subsection{Data analysis}

The comparison of the decrease of the densities of Planktothrix in the experiments with and without Daphnia was evaluated computing paired $t$-tests on the original data (Sokal and Rohlf, 1995).

The linear rate of decrease of the densities of Planktothrix in the exposures A-D was evaluated using linear regression analysis. Since the decrease of Planktothrix densities reflected an exponential pattern the data were log transformed before statistical analyses. The slopes of the regression lines were compared by an analysis of covariance (ANCOVA), with the 4 exposures representing the levels.
The increase of MC in Daphnia as a function of initial MC concentrations was evaluated computing both a linear (1) and exponential (2) model,

$\mathrm{MCD}=a+b \times \mathrm{MCi}$

$\mathrm{MCD}=a \times \exp (b \times \mathrm{MCi})$

where $M C_{i}$ and $M C_{D}$ are the $M C$ concentrations in the exposures $\mathrm{A}-\mathrm{D}$ at the beginning of the experiment and inside Daphnia individuals at a given exposure time, respectively. The models were computed and tested for 3 exposure times, i.e. 24,48 and $72 \mathrm{~h}$ (see also Fig. 2).

In the above analyses, ANCOVA and regression models were compared based on the Akaike information criterion (AIC) and ANOVA tests. Statistical analyses were calculated in R 3.0.0 (R Core Team, 2013).

\section{Results}

\subsection{Density of P. rubescens}

The density of $P$. rubescens in both experimental groups, with and without Daphnia, showed an exponential decrease over time. Fig. 1 shows the decrease of $P$. rubescens in two experiments with different cell densities. In experiments with a high cell density (Fig. 1a) and presence of Daphnia the average densities decreased considerably, from 53,630 to 5590 cells ml ${ }^{-1}$, already after $6 \mathrm{~h}$, while in Daphnia-free experiments, the decrease was less steep, i.e. from 71,025 cells ml $^{-1}$ to 50,230 cells ml$^{-1}$ (Fig. 1a). In experiments with low cell densities, the densities decreased less dramatically at the $6 \mathrm{~h}$ time-point, from 22,280 cells $\mathrm{ml}^{-1}$ to 12,365 cells ml ${ }^{-1}$ in presence of Daphnia. In Daphnia-free experiments Planktothrix showed a slight increase within the first $6 \mathrm{~h}$ (from 24,771 cells ml ${ }^{-1}$ to 29,289 cells $\mathrm{ml}^{-1}$ ), showing thereafter a gradual decrease (Fig. 1b). In experiments lasting $\geq 24 \mathrm{~h}$, filaments started to break to smaller sizes. In both cases, the decrease of Planktothrix in the grazing experiments with Daphnia was significantly larger compared with the experiments without Daphnia (paired $t$-test, as for Fig. $1 \mathrm{a}$ and $\mathrm{b}, p=0.01$ and $p<0.05$, respectively).

In all of the 6-days grazing experiments with Daphnia (cf. Fig. 2; Section 3.3), the densities of Planktothrix decreased at the same rate, i.e. following similar patterns of an exponential decrease in the 4 experiments A-D (ANCOVA, $p=0.53$ ). This demonstrated a comparable grazing effect of Daphnia on $P$. rubescens, apparently irrespective of the MCs concentrations/densities of MC containing $P$. rubescens used in the 4 experiments. 
(a)

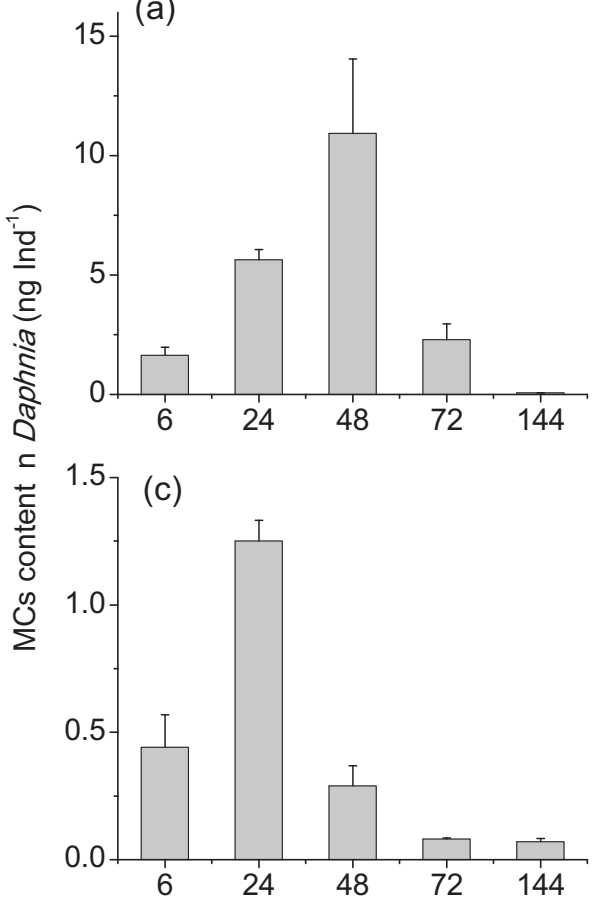

(b)

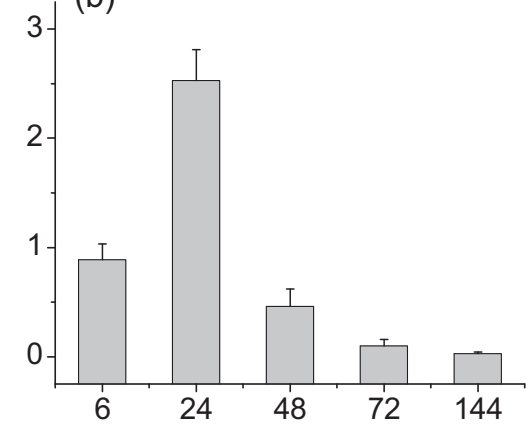

(d)

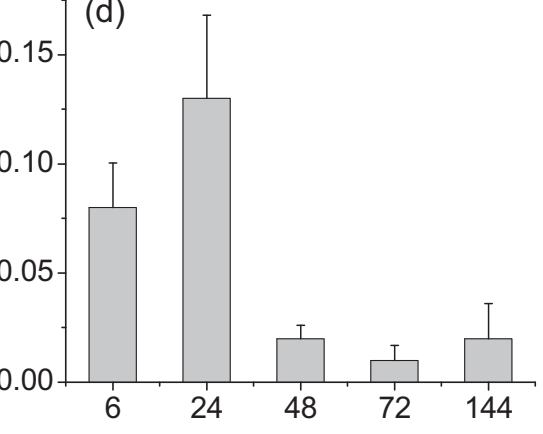

Hours

Fig. 2. MC accumulation in individuals of $D$. magna grazing on Planktothrix rubescens in four different exposures of decreasing toxic $P$. rubescens densities and consequently MC concentrations ( $\mathrm{a}=$ approx. $9, \mathrm{~b}=3.8, \mathrm{c}=2.4$ and $\mathrm{d}=0.6 \mu \mathrm{gl}^{-1}$ ) over 6 days of exposure time. Values are mean + SEM (standard errors of the means) of $n=3$ replicate experiments. Note the different scales of the $y$-axis in (a)-(d).

\subsection{Total MC concentration}

Total MC content (in filaments and water) in all beakers slightly decreased in the first $6 \mathrm{~h}$ but then remained approximately stable until $72 \mathrm{~h}$, with averages (mean $\pm \mathrm{SD}$ ) of $8.2 \pm 0.54,3.4 \pm 0.27$, $2.4 \pm 0.21$ and $0.52 \pm 0.07 \mu \mathrm{gl}^{-1}$ for experiments $\mathrm{A}, \mathrm{B}, \mathrm{C}$, and $\mathrm{D}$, respectively (data not shown). The dissolved:cell bound toxin ratio increased with time as $P$. rubescens population decreased and cell lysis induced liberation of internal MC added to the MC concentration in the ambient water.

\subsection{MC accumulation in Daphnia}

MC was detected in D. magna in all experiments containing toxic P. rubescens (Fig. 2). The highest MC concentrations in individual Daphnia were observed in experiment A (Fig. 2a), and the lowest in experiment D (Fig. 2d) and thus in accordance with the corresponding MC concentrations initially used in the experiments. In experiment A, the highest content of MC in Daphnia was reported at $48 \mathrm{~h}$ (about $11 \mathrm{ng}^{-1} \mathrm{ind}^{-1}$ ), while for experiments B, C and D it was observed at $24 \mathrm{~h}$ (about $2.5,1.2$, and $0.1 \mathrm{ng}^{\text {ind }}{ }^{-1}$, respectively). After these concentration peaks, the MC content in the body of Daphnia declined, and after 6 days ( $144 \mathrm{~h}$ ), MC concentrations were very low: $0.07,0.03,0.07$, and 0.02 ng ind $^{-1}$ in experiments $A, B, C$, and $\mathrm{D}$, respectively.

\subsection{Modelling the accumulation of MC in Daphnia}

Models of toxin accumulation demonstrated that during the first $24 \mathrm{~h}$, the toxin accumulation was linear, irrespective of the initial concentrations of MC in the experiments (Fig. 3a). However, after an additional $24 \mathrm{~h}$ toxin accumulation presented an exponential pattern (Fig. 3b), albeit with a considerable drop in the MC accumulation. This pattern was also clearly apparent at $72 \mathrm{~h}$ (Fig. 3c).
Both the linear (Fig. 3a) and the exponential (Fig. 3b and c) models of MC accumulation were highly significant (Table 1 ).

Owing to the almost constant content of MC in the experiments (Section 3.2), very similar results were obtained when comparing the MC accumulation in Daphnia with the actual concentrations of MC measured at $24 \mathrm{~h}, 48 \mathrm{~h}$ and $72 \mathrm{~h}$. Despite numerical comparability in the results, we did not continue with modelling of the MC concentrations in the Daphnia via ambient MC concentrations, as the internalized MC concentration within the Daphnia is the result of MC accumulation, metabolism and excretion and is not governed by a mere concentration diffusion model. The latter considerations are supported by the observed continuous accumulation of MCs in Daphnia and the increase in the dissolved:cell bound toxin ratio during the exposure experiments (Section 3.2).

\section{Discussion}

This study demonstrated the effective and significant grazing of $D$. magna over $P$. rubescens under controlled conditions in a microcosm experiment. In both experimental groups, with and without grazers, Planktothrix filaments declined over time, but a more remarkable decrease was observed in the presence of grazers. The disappearance of filaments from water in the experiments without Daphnia can be explained by disintegration of filaments

Table 1

Parameter estimates of the models fitted to the data in Fig. 3a and b. $a$ and $b$ are the parameters in Eq. (1) or (2). RSE, residual standard error (root mean square error, RMSE) on 10 degrees of freedom.

\begin{tabular}{llrlll}
\hline Time exposure & Model & $a$ & $b$ & RSE & $p$-Value \\
\hline 24 h(Fig. 3a) & Linear (1) & -0.15850 & 0.64746 & 0.502 & $<0.001$ \\
48 h(Fig. 3b) & Exponential (2) & 0.00122 & 1.00441 & 0.808 & $<0.001$ \\
72 h(Fig. 3c) & Exponential (2) & 0.06710 & 0.38610 & 0.593 & $<0.001$ \\
\hline
\end{tabular}



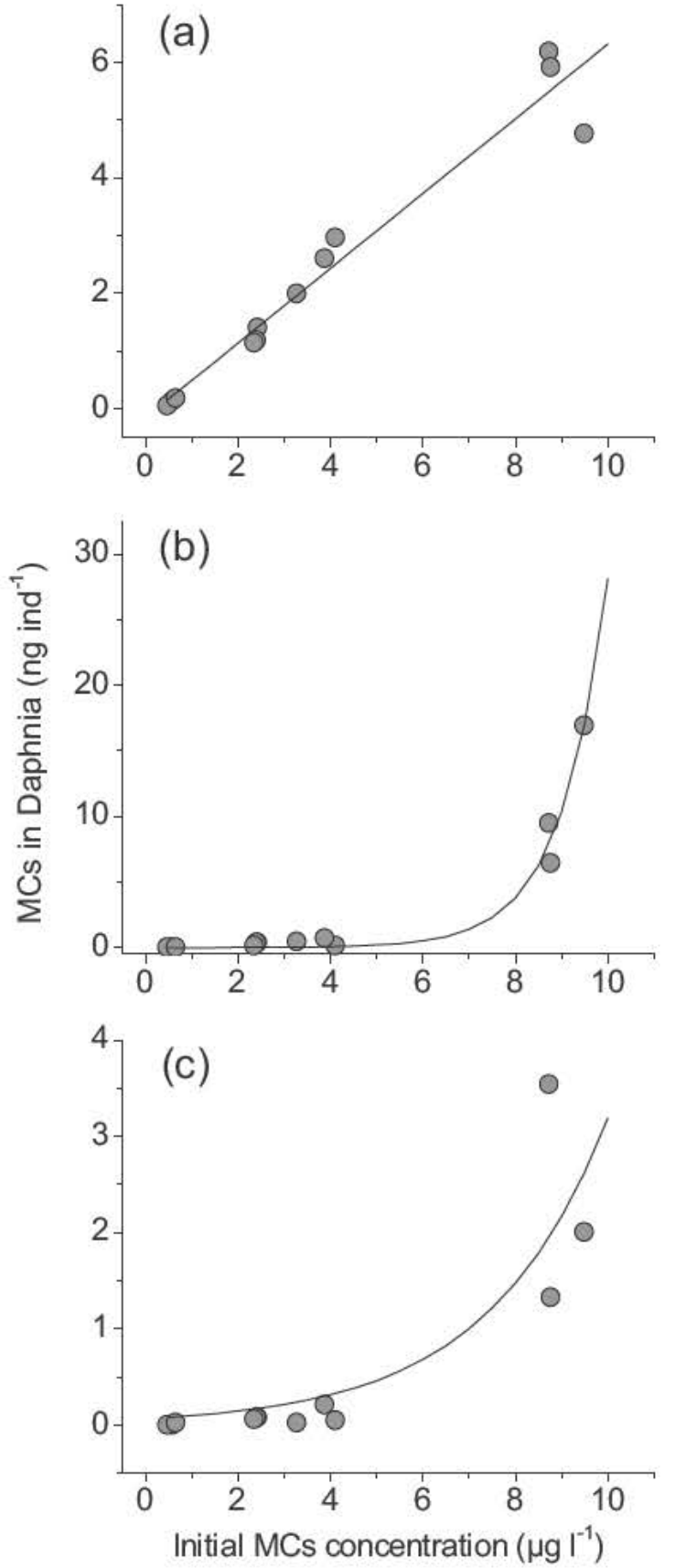

Fig. 3. Accumulation of MC in D. magna as a function of different initial concentrations of toxins, and after (a) $24 \mathrm{~h}$, (b) $48 \mathrm{~h}$ and (c) $72 \mathrm{~h}$. Data of three independent replicates per initial MC concentrations (MC containing Planktothrix rubescens densities) are shown. Note the different scales of the $y$-axis in (a)-(c).

and bacterial degradation and/or parasitic infection. In contrast, the decrease of filaments in experiments with Daphnia appears to result from the specific grazing activity of Daphnia, whereby the ingestion of shorter filaments that are more easily ingested could be favoured, as observed to occur after $24 \mathrm{~h}$. Parasitic chytrid fungi can cause mortality on most cyanobacteria. Nevertheless, Rohrlack et al. (2013) demonstrated that the production of microcystins, microviridins and anabaenopeptins, as the most common oligopeptides produced by most cyanobacteria, can reduce the virulence of chytrids to Planktothrix, thereby increasing the host's chance of survival. Therefore, the decrease of filaments in grazing experiments, as observed in the experiments presented here, is most likely the result of a combination of three factors, presence of grazers, disintegration of filaments and bacterial degradation, and/or possible interaction with parasitic chytrid fungi.

No mortality of Daphnia was observed during this study. However, the adverse effects of MCs on Daphnia such as reduced growth, survival and reproduction, have been investigated in many studies (DeMott and Moxter, 1991; Rohrlack et al., 2005; Trubetskova and Haney, 2006; Dao et al., 2010). Therefore, we cannot exclude toxic effects of MCs on the physiology of Daphnia during our experiments. However, the exponential MC accumulation due to active feeding in Daphnia after $48 \mathrm{~h}$ can be interpreted as an indirect indication of viability of daphnids in this experiment.

Accumulation of MCs in Daphnia was observed in all experiments containing toxic $P$. rubescens. However, in experiment A, with the highest MC concentration at the beginning of the experiment $\left(9 \mu \mathrm{gl}^{-1}\right)$, the maximum peak of MC accumulation in Daphnia was reached later $(48 \mathrm{~h})$ compared with experiments B-D, which had lower initial MC concentrations. Indeed, in experiments B-D the peak for MC content was recorded already at $24 \mathrm{~h}$.

The MC content in Daphnia decreased after $72 \mathrm{~h}$ in all of the experiments, most likely due to reduced uptake resulting from the degradation of $P$. rubescens filaments as well as due to increased metabolism and excretion of internalized MC. Indeed the number of $P$. rubescens filaments was decisively reduced after $72 \mathrm{~h}$. In conjunction with lowered MC uptake via filament ingestion, the rate of metabolism, e.g. conjugation to more hydrophilic moieties, and concomitant excretion would, in the sum of the uptake, metabolism and excretion kinetics, decrease the overall MC concentration within Daphnia. In view of the potentially higher dissolved MC concentrations in the ambient water post $72 \mathrm{~h}$, this also suggests that dissolved MCs in the ambient water are most likely not readily taken up by Daphnia.

To characterize the kinetics of MC accumulation in D. magna, we used models to estimate how much of the available MC in different diets (here $P$. rubescens filaments) would accumulate in the body of Daphnia over time. We found that the degree and pattern of MC accumulation in D. magna was directly related to the initial MC and to the exposure time. Within the first $24 \mathrm{~h}$ of exposure, a linear relationship was observed between initial ambient MC concentrations in the food and the MC concentrations detected per individual daphnid (Fig. 3a). Subsequent to the first $24 \mathrm{~h}$ the toxin accumulation followed an exponential pattern, with proportionally higher MC concentrations at higher initial ambient MC concentrations in the food. The exponential pattern at $48 \mathrm{~h}$ (Fig. 3b) resulted not only from the larger accumulation of MC at higher initial ambient MC concentrations in the food, but also from concomitantly decreasing MC containing food in the experiments with lower initial MC concentrations (see Fig. 2). As accumulation kinetics were evaluated considering the initial MC concentrations in the food, the actual accumulation kinetics may have been underestimated, thus suggesting that MC retained within Daphnia could be not only dependent on MC availability in food and on the corresponding grazing activity. Indeed, partial or full inhibition of digestion and detoxification pathways, resulting from high internalized MC concentrations could have evolved. Rohrlack et al. (2001) previously suggested that MC detoxification pathways in cladocerans could be more efficient at low MC concentrations. Correspondingly, Chen et al. (2005) showed that while low concentrations of dissolved MC-LR had no harmful consequences for D. magna, high concentrations and long-term exposure resulted in a reduction of antioxidant enzyme activities, most likely resulting from an overburdening of the detoxification system by MC metabolism. Indeed, at low MC concentrations the crucial protein phosphatases were not entirely inhibited, thereby allowing at least partial functioning of signal transduction, i.e. enzyme activation/deactivation control pathways. Overall, the latter observations fit with the hypothesis 
that higher proportions of toxic filaments are able to shift the balance between accumulation and excretion/detoxification towards a greater accumulation of $\mathrm{MC}$ in grazers, with a corresponding exponential increase of $\mathrm{MC}_{\mathrm{D}}$ as a function of $\mathrm{MC}_{\mathrm{i}}$.

The models that we elucidated with these experiments could have important implications for the transfer of toxins along the trophic webs. Nevertheless, our study showed that with the existence of non-linear patterns of MC accumulation, trophic transfer of MC to higher trophic levels would be strongly dependent on the trophic status of water bodies and the degree of toxicity of cyanobacterial strains characterized by different toxin per cell quota. The presence of MC at different trophic levels has been reported by many studies (Ibelings et al., 2005; Lehman et al., 2010). Sotton et al. (2014) analyzed the accumulation of MC in the whitefish (Coregonus), which is one of the most important commercial fish in the peri-alpine region. The whitefish was found below the thermocline, where metalimnetic blooms of $P$. rubescens also occurred. Though an unintentional ingestion of filaments was expected from earlier experiments by Ernst et al. (2007, 2009), after analysing the whitefish gut only a few or no filaments were observed. Instead, zooplanktonic herbivores were clearly demonstrated as the vectors of MCs to whitefish by encapsulating grazed cyanobacteria through their diel vertical migration. Actually, 75\% and $21 \%$ of the total MCs in the white fish came from Chaoborus larvae and Daphnia, respectively.

The results obtained in this study require to be interpreted with care. The statistical parameters representing the bioaccumulation models are valid only in this particular experimental system and with the cyanobacterial cell density curves reported. However, the experiments showed quite clearly how the relationship between the accumulation of MC in Daphnia and the initial concentrations of toxic cyanobacteria and toxins (i.e. the variables mostly related to eutrophication) can be described with general linear and exponential models, depending on the exposure time. Needless to state that in order to decisively improve the bioaccumulation model, the corresponding kinetic parameters for MC metabolism and excretion in Daphnia would be required. The latter kinetic parameters would also allow elucidation of whether at higher internal MC concentrations, metabolism and excretion of MCs can be overwhelmed or even inhibited, thus resulting in the observed overall accumulation of MCs.

The experimental setup we used does not adequately represent the natural environment. Indeed, the grazing activity by Daphnia was influenced by the availability of shorter filaments in the algal cultures. Moreover, the experiments could be biased by the tendency of Planktothrix to degrade (microbially) in these small mesocosms. However, considering that the rate of decrease (and therefore food consumption) in the abundances of $P$. rubescens was similar in the 4 (A-D) grazing experiments, the results seems to further confirm that a proportionally larger accumulation of MC can be observed in presence of more toxic variants of cyanobacteria. Considering the above weaknesses in the experimental setup, the results should be verified in larger mesocosms, with durable and long-living populations of Planktothrix.

The possibility to further generalize the results of these experiments should also take into consideration the characteristics of $D$. magna. This species in one of the large grazers, i.e. individuals used in this work were around $3 \mathrm{~mm}$, and thus much larger than other common Daphnia inhabiting lentic waters. For example, in Lake Garda, and in many other large subalpine lakes, waters are populated by smaller individuals of Daphnia hyalina/galeata, several of them with dimensions of $1 \mathrm{~mm}$ and therefore with a smaller ability to graze on long filamentous algae (Salmaso and Naselli Flores, 1999). Moreover, differences in hydrophobicity among MC variants must also be taken into account to interpret the bioaccumulation patterns (Ward and Codd, 1999). In this experiment [D-Asp ${ }^{3}$ ] MCRR produced by Planktothrix is more hydrophilic than MC-LR, the experimentally most employed variant of MC. In the presence of more hydrophobic MC, e.g. MC-LA, -LF or -LW, even lower depuration rates and thus higher accumulation rates would be expected in daphnids, thus emphasizing that not only the cyanobacterial species and their anatomical descriptors, but also the specific MC produced may be key factors governing the accumulation, depuration and thus residual time of MC within daphnids. The latter will be key determinants for the potential trophic transfer of MC within a given surface water system.

\section{Conflict of interest}

None.

\section{Author contributions}

The experiment was planned by all the authors. S. Shams conducted the experiment. L. Cerasino performed the LC-MS/MS analysis. The models were prepared by N. Salmaso. The manuscript was written by S. Shams and revised by L. Cerasino, N. Salmaso and D. R. Dietrich.

\section{Acknowledgements}

This study was funded by the EU Central Europe Programme (EULAKES Project, 2CE243P3). We thank the European Cooperation in Science and Technology COST Action ES1105 CYANOCOST for networking and knowledge-transfer support. We greatly acknowledge the logistic support and collaboration of ARPA-Veneto (Regional Agency for Environmental Protection). This work was also supported by a fellowship to S.S. from the IASMA Research and Innovation Centre, E. Mach Foundation. We thank Jayant Ranjan for help provided during the counting of Planktothrix in the first phases of the experiment.

\section{References}

Benndorf, J., Boing, W., Koop, J., Neubauer, I., 2002. Top-down control of phytoplankton: the role of time scale, lake depth and trophic state. Freshwater Biology 47, 2282-2295.

Cerasino, L., Salmaso, N., 2012. Diversity and distribution of cyanobacterial toxins in the Italian subalpine lacustrine district. Oceanological and Hydrobiological Studies 41, 54-63.

Chen, W., Song, L., Ou, D., Gan, N., 2005. Chronic toxicity and responses of several important enzymes in Daphnia magna on exposure to sublethal microcystin-LR. Environmental Toxicology 20, 323-330.

Dao, T.S., Do-Hong, L.C., Wiegand, C., 2010. Chronic effects of cyanobacterial toxins on Daphnia magna and their offspring. Toxicon 55, 1244-1254.

Davis, P.A., Dent, M., Parker, J., Reynolds, C.S., Walsby, A.E., 2003. The annual cycle of growth rate and biomass change in Planktothrix spp. in Blelham Tarn, English Lake District. Freshwater Biology 48, 852-867.

DeMott, W.R., 1986. The role of taste in food selection by freshwater zooplankton. Oecologia 69, 334-340.

DeMott W.R., Moxter, F., 1991. Foraging on cyanobacteria by copepods: responses to chemical defenses and resource abundance. Ecology 72, 1820-1834.

DeMott, W.R., 1995. The influence of prey hardness on Daphnia selectivity for large prey. Hydrobiologia 307, 127-138.

DeMott, W.R., 1999. Foraging strategies and growth inhibition in five daphnids feeding on mixtures of a toxic cyanobacterium and a green alga. Freshwater Biology 42, 263-274.

Dietrich, D.R., Hoeger, S.J., 2005. Guidance values for microcystin in water and cyanobacterial supplement products (blue-green algae supplements): a reasonable or misguided approach? Toxicology and Applied Pharmacology 203, $273-289$.

Elser, J.J., 1999. The pathway to noxious cyanobacteria blooms in lakes: the food web as the final turn. Freshwater Biology 42, 537-543.

Ernst, B., Hoeger, S.J., O’Brien, E., Dietrich, D.R., 2007. Physiological stress and pathology in European whitefish (Coregonus lavaretus) induced by subchronic exposure to environmentally relevant densities of Planktothrix rubescens. Aquatic Toxicology $82,15-26$. 
Ernst, B., Hoeger, S.J., O'Brien, E., Dietrich, D.R., 2009. Abundance and toxicity of Planktothrix rubescens in the pre-alpine Lake Ammersee, Germany. Harmful Algae 8, 329-342.

Ferrão-Filho, A.S., Kozlowsky-Suzuki, B., Azevedo, S.M.F.O., 2002. Accumulation of microcystins by a tropical zooplankton community. Aquatic Toxicology 59, 201-208.

Guzzella, L., Ghislanzoni, L., Pozzoni, F., Cerasino, L., Salmaso, N., 2010. Determinazione di tossine algali (microcistine e nodularina) nelle acque superficiali. Notiziario dei metodi analitici, IRSA-CNR 1, 17-31.

Hawkins, P.R., Lampert, W., 1989. The effect of Daphnia body size on filtering rate inhibition in the presence of a filamentous cyanobacterium. Limnology and Oceanography 34, 1084-1089.

Hulot, F.D., Carmignac, D., Legendre, S., Yepremian, C., Bernard, C., 2012. Effects of microcystin-producing and microcystin-free strains of Planktothrix agardhii on long-term population dynamics of Daphnia magna. Journal of Limnology 48, 337-347.

Ibelings, B.W., Bruning, K., De Jonge, J., Wolfstein, K., Pires, L.M., Postma, J., Burger, T., 2005. Distribution of microcystins in a lake foodweb: no evidence for biomagnification. Microbial Ecology 49, 487-500.

Jungmann, D., Henning, M., Jüttner, F., 1991. Are the same compounds in Microcystis responsible for toxicity to Daphnia and inhibition of its filtering rate? Int. Rev. Gesamten Hydrobiol. 76, 47-56.

Jungmann, D., 1995. Isolation, purification, and characterization of new Daphniatoxic compound from axenic Microcystis aeruginosa strain PCC7806. Journal of Chemical Ecology 21, 1665-1676.

Kurmayer, R., Jüttner, F., 1999. Strategies for the co-existence of zooplankton with the toxic cyanobacterium Planktothrix rubescens in Lake Zürich. Journal of Plankton Research 21, 659-683.

Kurmayer, R., 2001. Competitive ability of Daphnia under dominance of non-toxic filamentous cyanobacteria. Hydrobiologia 442, 279-289.

Lawton, L., Marsalek, B., Padisák, J., Chorus, I., 1999. Determination of cyanobacteria in the laboratory. In: Chorus, I., Bartram, J. (Eds.), Toxic Cyanobacteria in Water: A Guide to Their Public Health Consequences, Monitoring and Management. E \& FN Spon, an imprint of Routledge, pp. 347-367.

Lehman, P.W., Teh, S.J., Boyer, G.L., Nobriga, M.L., Bass, E., Hogle, C., 2010. Initial impacts of Microcystis aeruginosa blooms on the aquatic food web in the San Francisco Estuary. Hydrobiologia 637, 229-248.

Lemaire, V., Brusciotti, S., van Gremberghe, I., Vyverman, W., Vanoverbeke, J., De Meester, L., 2012. Genotype $\times$ genotype interactions between the toxic cyanobacterium Microcystis and its grazer, the waterflea Daphnia. Evolutionary Applications 5, 168-182.

Metcalf, J.S., Codd, G.A., 2012. Cyanotoxins. In: Whitton, B.A. (Ed.), Ecology of Cyanobacteria II. Springer, pp. 651-675.

Nadin-Hurley, C.M., Duncan, A., 1976. A comparison of daphnid gut particles with sestonic particles present in two Thames Valley reservoirs throughout 1970 and 1971. Freshwater Biology 6, 109-123.

Oberhaus, L., Gélinas, M., Pinel-Alloul, B., Ghadouani, A., Humbert, J.F., 2007. Grazing of two toxic Planktothrix species by Daphnia pulicaria: potential for bloom control and transfer of microcystins. Journal of Plankton Research 29, 827-838.

Paerl, H.W., Hall, N.S., Calandrino, E.S., 2011. Controlling harmful cyanobacterial blooms in a world experiencing anthropogenic and climatic-induced change. Science of the Total Environment 409, 1739-1745.

Pires, L.M.D., Bontes, B.M., Samchyshyna, L., Jong, J.P., Van Donk, E., Ibelings, B.W., 2007. Grazing on microcystin-producing and microcystin-free phytoplankters by different filter-feeders: implications for lake restoration. Aquatic Sciences 69, 534-543.

Porter, K.G., McDonugh, R., 1984. The energetic cost of response to blue-green algae filaments by cladocerans. Limnology and Oceanography 29, 365-369.

Puddick, J., 2013. Spectroscopic Investigations of oligopeptides from aquatic cyanobacteria: characterisation of new oligopeptides. In: Development of Microcystin Quantification Tools and Investigations into Microcystin Production. The University of Waikato.

R Core Team, 2013. R: A Language and Environment for Statistical Computing. $\mathrm{R}$ Foundation for Statistical Computing, Vienna, Austria http://www. R-project.org/
Reichwaldt, E.S., Abrusan, G., 2007. Influence of food quality on depth selection of Daphnia pulicaria. Journal of Plankton Research 29, 839-849.

Reichwaldt, E.S., Song, H., Ghadouani, A., 2013. Effects of the distribution of a toxic Microcystis bloom on the small scale patchiness of zooplankton. PLoS ONE 8 (6), e66674.

Rohrlack, T., Dittmann, E., Börner, T., Christoffersen, K., 2001. Effects of cell-bound microcystins on survival and feeding of Daphnia spp. Applied and Environmental Microbiology 67, 3523-3529.

Rohrlack, T., Christoffersen, K., Dittmann, E., Nogueira, I., Vasconcelos, V., Börner, T. 2005. Ingestion of microcystins by Daphnia: intestinal uptake and toxic effects. Limnology and Oceanography 50, 440-448.

Rohrlack, T., Christiansen, G., Kurmayer, R., 2013. Putative antiparasite defensive system involving ribosomal and nonribosomal oligopeptides in cyanobacteria of the genus Planktothrix. Applied and Environmental Microbiology 79, 26422647.

Rott, E., Salmaso, N., Hoehn, E., 2007. Quality control of Utermöhl based phytoplankton biovolume estimates - an easy task or a Gordian knot? Hydrobiologia 578, 141-146.

Salmaso, N., Naselli Flores, L., 1999. Studies on the zooplankton of the deep subalpine Lake Garda. Journal of Limnology 58, 66-76.

Salmaso, N., Morabito, G., Mosello, R., Garibaldi, L., Simona, M., Buzzi, F., Ruggiu, D., 2003. A synoptic study of phytoplankton in the deep lakes south of the Alps (lakes Garda, Iseo, Como, Lugano and Maggiore). Journal of Limnology 62, 207-227.

Salmaso, N., Boscaini, A., Shams, S., Cerasino, L., 2013. Strict coupling between the development of Planktothrix rubescens and microcystin content in two nearby lakes south of the Alps (lakes Garda and Ledro). Annales de Limnologie - International Journal of Limnology, http://dx.doi.org/10.1051/limn/2013064.

Sivonen, K., Jones, G., 1999. Cyanobacterial toxins. In: Chorus, 1., Bartram, J. (Eds.), Toxic Cyanobacteria in Water: A Guide to Public Health. Significance, Monitoring and Management. E and FN Spon, London, United Kingdom, pp. 41-111.

Sivonen, K., Börner, T., 2008. Bioactive compounds produced by cyanobacteria. In: Herrero, A., Flores, E. (Eds.), The Cyanobacteria. Molecular Biology, Genomics and Evolution. Caister Academic Press, Norfolk, United Kingdom, pp. 159197.

Sokal, R.R., Rohlf, F.J., 1995. Biometry: The Principles and Practice of Statistics in Biological Research. Freeman, New York, pp. 887.

Sotton, B., Guillard, J., Anneville, O., Maréchal, M., Savichtcheva, O., Domaizon, I., 2014. Trophic transfer of microcystins through the lake pelagic food web: evidence for the role of zooplankton as a vector in fish contamination. Science of the Total Environment 466-467, 152-163.

Spoof, L., 2005. Microcystins and nodularins. In: Meriluoto, J., Codd, G.A. (Eds.), Toxic Cyanobacterial Monitoring and Cyanotoxin Analysis. Abo Akademi University Press, Abo, Finland, pp. 15-39.

Thostrup, L., Christoffersen, K., 1999. Accumulation of microcystin in Daphnia magna feeding on toxic Microcystis. Archiv für Hydrobiologie 145, 447-467.

Trubetskova, I.L., Haney, J.F., 2006. Effects of differing concentrations of microcystin-producing Microcystis aeruginosa on growth, reproduction, survivorship and offspring of Daphnia magna. Archiv für Hydrobiologie 167, 533546

Tsuji, K., Naito, S., Kondo, F., Ishikawa, N., Watanabe, M.F., Suzuki, M., Harada, K.-I., 1994. Stability of microcystins from cyanobacteria: effect of light on decomposition and isomerization. Environmental Science and Technology 28, 173177.

Ward, C.J., Codd, G.A., 1999. Comparative toxicity of four microcystins of different hydrophobicities to the protozoan, Tetrahymena pyriformis. Journal of Applied Microbiology 86, 874-882.

Wojtal-Frankiewicz, A., Bernasińska, J., Jurczak, T., Gwoździński, K., Frankiewicz, P., Wielanek, M., 2013. Microcystin assimilation and detoxification by Daphnia spp. in two ecosystems of different cyanotoxin concentrations. Journal of Limnology 72, 154-171.

Zhang, D., Xie, P., Chen, J., Dai, M., Qiu, T., Liu, Y., Liang, G., 2009. Determination of microcystin-LR and its metabolites in snail (Bellamya aeruginosa), shrimp (Macrobrachium nipponensis) and silver carp (Hypophthalmichthys molitrix) from Lake Taihu, China. Chemosphere 76, 974-981. 